\title{
O PROJETO PORTO MARAVILHA E O RENT GAP DE NEIL SMITH
}

\section{THE PORTO MARAVILHA PROJECT AND THE NEIL SMITH'S RENT GAP THEORY}

\section{Renato Domingues Fialho Martins}

Centro Federal de Educação Tecnológica Celso Suckow da Fonseca, Itaguaí, RJ, Brasil
R E S U M O : A Operação Urbana Consorciada (OUC) Porto Maravilha refere-se a um conjunto de intervençóes urbanisticas, viárias, imobiliárias e financeiras na zona portuária do Rio de Janeiro, levado a cabo por um consórcio que envolve o poder público municipal e grandes empreiteiras transnacionais. Trata-se de uma operação urbana de evidente destaque, sendo a maior parceria público-privada do país. O objetivo deste artigo é analisar a OUC Porto Maravilha a partir da formulação teórica do rent gap, proposta por Neil Smith, e a consequente discussão sobre o conceito de gentrificação. A ideia é verificar se a teoria do rent gap pode ajudar a compreender esse grupo de intervençóes urbanas. Além disso, pretende-se examinar os limites e virtudes do rent gap. Várias questóes são consideradas no estudo, tais como: (1) é possivel importar uma teoria formulada para cidades de paises centrais e aplicá-la na experiência carioca? Em caso positivo, (2) quais distinçôes devem ser sublinhadas e quais precauçôes precisam ser tomadas?

P A L A V R A S - C H A V E : Porto Maravilha; gentrificação; rent gap; empreendedorismo urbano.

\section{INTRODUÇÃO}

A Operação Urbana Consorciada (OUC) Porto Maravilha refere-se a um conjunto de intervenções urbanísticas, viárias, imobiliárias e financeiras levado a cabo por um consórcio que envolve o poder público municipal e grandes empreiteiras transnacionais ${ }^{1}$. Trata-se da maior parceria público-privada do país, conforme destacam os empreendedores ${ }^{2}$.

Essas intervençôes ocorrem na zona portuária, que compreende os bairros Santo Cristo, Gamboa, Saúde, parte do Caju e São Cristóvão, todos localizados na área central da cidade do Rio de Janeiro. Tais bairros comportam, ainda, os morros da Providência, do Pinto, do Livramento e da Conceição. Eles são de grande relevância para a cidade, pois foram uma das primeiras ocupaçôes após a chegada dos europeus à baía de Guanabara, além de serem palco de manifestaçôes relacionadas à cultura negra.

Os bairros portuários tornaram-se espaços de importantes atividades econômicas, industriais e comerciais, tendo experimentado o seu auge após a reforma portuária de 1904-1911. A partir da década de 1960, essa zona se converteu numa área de
1 Instituída pela lei municipal complementar $n^{\circ} 101 /$ 2009, a OUC Porto MaraviIha é conduzida pelo Consórcio Porto Novo S.A., que envolve o poder público municipal e grandes empreiteiras privadas (Odebrecht, OAS e Carioca Engenharia).

2 Disponível em: <http:// portomaravilha.com.br/materias/entenda-o-negocio/ e-o-n.aspx>. Acesso em: 15 de ago. 2015. 
3 Disponível em: <http:// portomaravilha.com.br/ web/sup/OperUrbana Apresent.aspx>. Acesso em: 10 maio 2015. obsolescência, com a deterioraçáo dos prédios, o sucateamento dos equipamentos urbanos, o predomínio de moradores mais pobres e a estigmatização espacial, associada à imagem de área ligada à prostituição, ao comércio de drogas ilícitas e à violência.

Figura 1: Mapa do perímetro da OUC Porto Maravilha

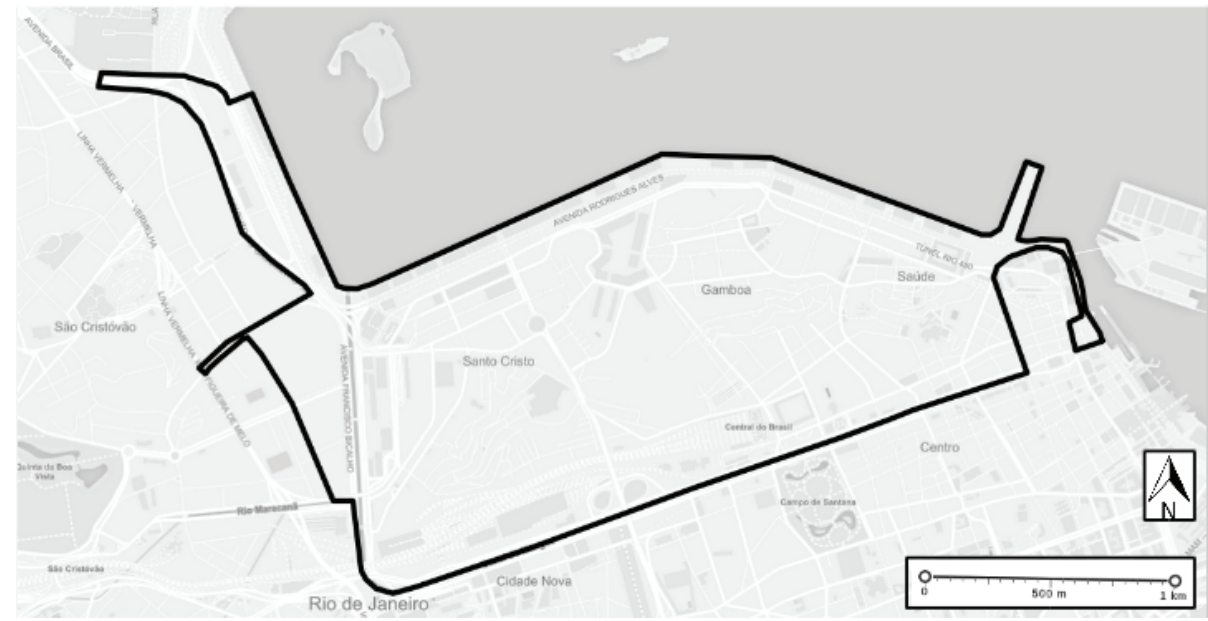

Fonte: Elaborado pelo autor com base na Lei municipal complementar $n^{\circ} 101$, de 23/11/09.

Diante de tais condiçóes, a meta principal do Porto Maravilha é, nas palavras dos empreendedores, "preparar a região portuária, há muitos anos relegada a segundo plano, para se integrar a $[\mathrm{o}]$ processo de desenvolvimento, já que o Rio de Janeiro dá claros sinais de uma nova dinâmica econômica, impulsionada pelos grandes eventos que vão ocorrer na cidade nos próximos anos"3.

O objetivo deste artigo é efetuar uma análise da OUC Porto Maravilha a partir da formulação teórica do rent gap proposta por Neil Smith e da consequente discussão sobre o conceito de gentrificação. Busca-se verificar se a teoria de Smith pode ajudar a compreender as intervençóes urbanas no Rio de Janeiro, apontando alguns de seus limites e virtudes. Várias questóes são consideradas, tais como: é possível importar uma teoria formulada para cidades de países centrais e aplicá-la na experiência carioca? Em caso positivo, quais distinçóes e cuidados devem ser sublinhados? Passaram-se quatro ou cinco décadas desde que o processo de gentrificação começou a ganhar fôlego nos países centrais. Considerando isso, quais as implicaçóes desse hiato temporal em relação às experiências norte-americanas e europeias para o caso carioca?

Para dar conta dessa tarefa, foram adotados alguns procedimentos metodológicos. Em primeiro lugar, revisou-se a bibliografia acerca do debate sobre gentrificação e rent gap. A proposta teórica de Smith foi posta em confronto com alguns de seus críticos. É importante destacar que apenas algumas críticas (favoráveis ou contrárias) foram expostas, apesar de ter-se em conta a amplitude da discussão. Em seguida, pesquisaram-se dados do mercado imobiliário carioca a fim de aplicar o rent gap ao Porto Maravilha. O resultado dessa pesquisa e a análise dos dados encontram-se na seção 5. Por fim, foram inventariadas as principais informaçôes sobre o projeto examinado e sobre o processo de esvaziamento econômico da zona portuária que precedeu o Porto Maravilha. 


\section{CONVERSÃO DA ZONA PORTUÁRIA EM ÁREA DE OBSOLESCÊNCIA}

Em 1904, começaram as obras da modernização portuária. Os bairros que compunham essa área passaram por um processo de rápida adequação às novas exigências de uma cidade que crescia a passos largos, com a construção de grandes armazéns, depósitos e edificaçôes que visavam a atender as tarefas do porto.

Durante a primeira metade do século XX, o centro da cidade apresentava um perfil demográfico claramente proletarizado. Baseado nos dados do censo de 1950, Geiger (1960, p. 32) destaca que, entre os 16 distritos do município, o centro era um dos que apresentavam os maiores percentuais de operários.

Como bem explica Smith (1996), a gentrificação, em geral, é precedida por um processo de deterioração física e econômica. No caso pesquisado, após a década de 1950, os bairros do porto passaram a enfrentar um cenário de degradação estrutural e de esvaziamento econômico. Há uma carência de estudos minuciosos que apontem as razóes desse processo. A seguir, serão apresentadas algumas explicaçóes possíveis para ele.

Esses bairros têm certa importância nos setores industriais ${ }^{4}$ desde meados do século XIX. Nesse sentido, o deslocamento das indústrias para áreas mais afastadas do centro da cidade pode ter contribuído para seu esvaziamento econômico (FREITAS FILHO, 2004). Outra razão comumente citada relaciona-se ao declínio relativo das atividades do porto carioca diante da concorrência de outros portos brasileiros - fato também associado à própria estagnação da economia fluminense após a transferência da capital brasileira para Brasília, em 1960 (OSÓRIO; VERSIANI, 2013). É possível dizer, igualmente, que as mudanças tecnológicas na operação do porto influenciaram seu declínio econômico. Ao longo da segunda metade do século XX, foram introduzidos máquinas, guindastes e equipamentos que substituíram parte dos estivadores, o que ocasionou a redução do número de trabalhadores necessários para a operação portuária. Em consequência disso, o comércio, que dependia da circulação dos portuários nos bairros, encolheu.

Além desses elementos, as mudanças viárias no centro do Rio também costumam ser destacadas como responsáveis pelo esvaziamento da zona portuária. A abertura da avenida Presidente Vargas, concluída em fins de 1944, acompanhada da demolição de vários imóveis, cortiços e igrejas, inaugurou um novo eixo vetorial no centro e, posteriormente, passou a concentrar as atividades comerciais. Essa avenida, de sentido leste-oeste, se estende ao longo da área portuária. O CBD (central business district) em formação configurou-se ao sul dessa via e ao longo da avenida Rio Branco, de "costas", portanto, para o porto. Ao lado disso, embora talvez seja menos relevante, é preciso acrescentar a dimensão natural: a avenida Presidente Vargas segue paralela a uma sequência de morros - Conceição, Livramento, Providência, Pinto e São Diogo -, os quais constituem uma barreira física entre o CBD e o porto.

Houve ainda a construção do elevado da Perimetral, cujo primeiro trecho foi inaugurado em 1960. A Perimetral contornava o limite norte na zona portuária, sobre a avenida Rodrigues Alves. Ademais, devem ser citadas as construçóes, em 1963, do túnel Santa Bárbara e do viaduto São Sebastião sobre o bairro do Catumbi, que também ligam a Zona Sul às principais avenidas de acesso à cidade. Esses três
4 "Às atividades comerciais e portuárias em franca expansão, acrescente a presença de atividades manufatureiras, que na década de 1840 registraram significativo avanço" (LAMARÃO, 2006, p. 40). 
exemplos de mudanças viárias contribuíram para tornar a zona portuária um conjunto de "bairros de passagem", nos quais as vias de maior circulação estâo localizadas no seu perímetro. As ruas internas, curtas, estreitas e sinuosas, assim como os becos, ladeiras e vielas dos morros permaneceram à margem das mudanças.

Figura 2: Principais vias próximas à zona portuária do Rio de Janeiro

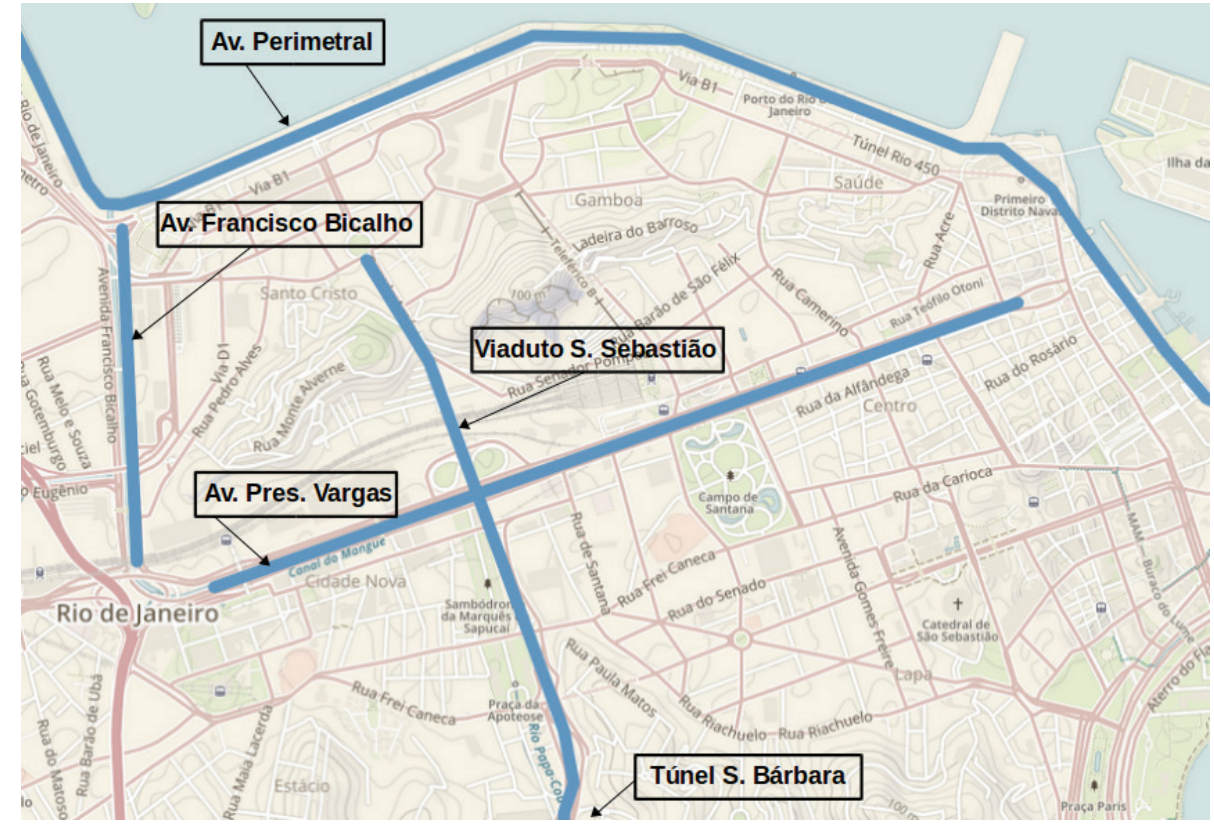

Fonte: Elaborado pelo autor a partir da ferramenta MapBox.

Publicado durante o início do processo de degradação urbana, o artigo de Maria Therezinha Segadas Soares sublinha elementos que iluminam o entendimento desse processo. A autora identifica, nos anos 1960, duas fisionomias distintas nos bairros próximos ao porto: (a) as áreas aterradas, onde notava-se a presença das atividades portuárias, desde a Praça Mauá até a Ponta do Caju. Segundo Soares, "depósitos, armazéns, estações de passageiros, frigoríficos, moinhos, depósitos de gás e combustíveis, cais de minérios, linhas ferroviárias cruzando as ruas para atingirem o porto e um movimento constante de carga e descarga caracteriza[va]m esta área”; (b) as áreas não aterradas, nas quais "uma população pobre viv[ia] nos sobrados antigos da área vizinha ao porto, que se integra[va] na zona de obsolescência da cidade, e que [era] habitada por uma classe trabalhadora, [...] que aí encontrou alojamento barato e próximo do centro" (SOARES, 1965, p. 340-341).

$\mathrm{O}$ artigo também aborda o deslocamento das indústrias, que tiveram um relevante papel para o crescimento da cidade nos anos anteriores. De acordo com a autora, "devido à escassez de terrenos amplos e baratos, decorrente dos problemas do sítio urbano, as grandes indústrias buscaram a periferia da cidade para a sua instalação" (SOARES, 1965, p. 342). 
Referente à estrutura urbana carioca, Soares classifica a cidade em quatro espaços: centro, área de obsolescência, bairros e subúrbios, conforme mostra a Figura 3. A área de obsolescência definida pela autora, na qual está incluída a zona portuária, abrange a Lapa, Paula Matos (Santa Teresa), a Glória, parte do Catete, o Mangue (redondezas da avenida Francisco Bicalho), a Gamboa e parte de São Cristóvão. Já tinham se passado 20 anos desde a inauguração da avenida Presidente Vargas no momento de publicação do artigo de Soares, mas essa via, com exceção do cruzamento com a Rio Branco, ainda não estava ocupada pelos arranha-céus atuais. Por isso, curiosamente, ela foi incluída na área de obsolescência.

Figura 3: Estrutura urbana do município do Rio de Janeiro na década de 1960

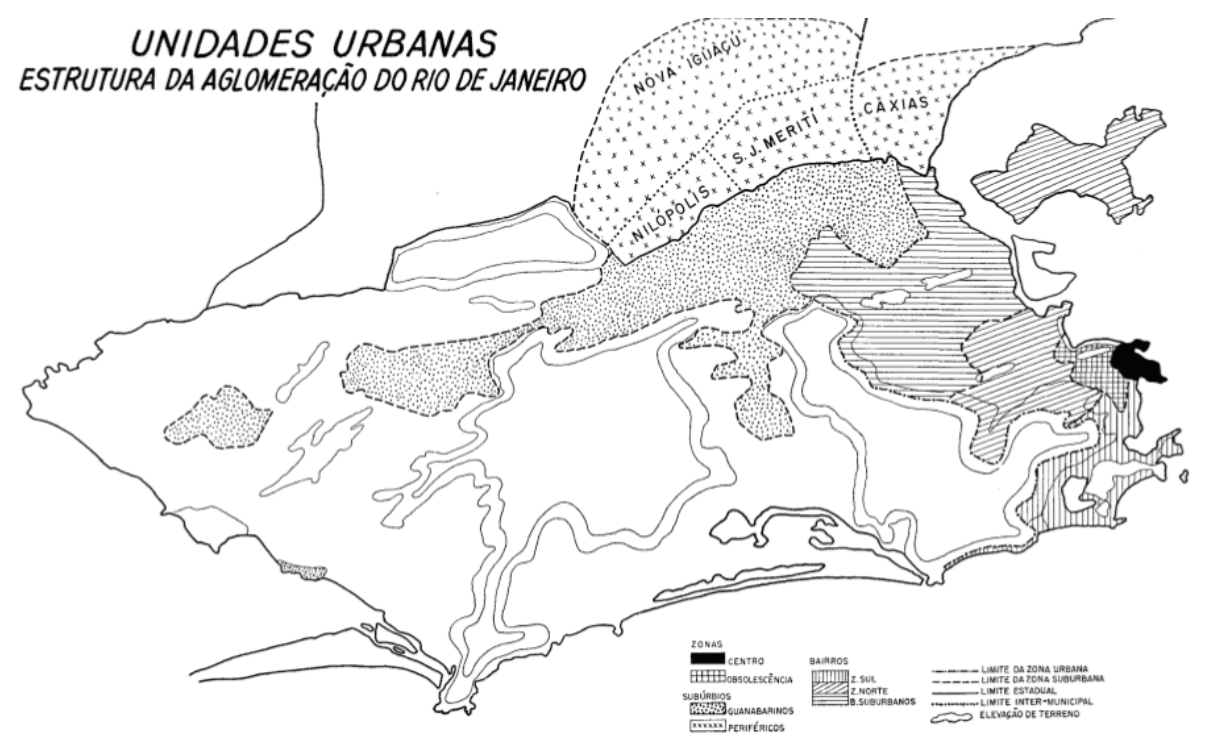

Fonte: Soares (1965, p. 356).

A autora descreve os bairros como espaços em que "prédios velhos, sobrados estreitos ou pequenas casas geminadas de frente de rua [eram] utilizados para os mais diversos fins ou habitados por pessoas de baixo padrão social" (SOARES, 1965, p. 358). Uma descrição semelhante a certa parte da zona portuária dos dias atuais.

É interessante compreender as explicaçóes de Soares para as causas que levaram à formação dessa área de obsolescência no Rio de Janeiro, pois elas serão úteis para examinar o conceito de rent gap nas próximas seções.

A pesquisadora afirma que a zona central e comercial (por vezes também industrial, é necessário acrescentar) de uma cidade, à medida que se expande horizontalmente, acaba ocupando zonas até entâo exclusivamente residenciais. Os moradores dessas localidades, incomodados com seus novos usos, tendem a buscar freguesias mais agradáveis. O deslocamento se intensifica com a expansão espacial dos transportes em direção às novas zonas residenciais. No caso carioca, a população de renda mais elevada tomou o caminho em direção à Zona Sul (Botafogo, Laranjeiras, Copacabana); a de renda média, para os bairros da Zona Norte (Tijuca, Vila Isabel, Grajaú, Andaraí); já a população de renda mais baixa seguiu o curso dos bairros suburbanos, ao longo das estações das linhas ferroviárias (SOARES, 1965, p. 360-361). 
A explicação da autora não dá conta de todo o fenômeno; contudo, há nela observaçôes relevantes, como esta: "Constituiu-se, assim, uma área desvalorizada para residência, com um valor potencial grande, decorrente das previsóes do provável avanço do centro sobre ela. $\mathrm{O}$ valor real dessa área não é desprezível, por sua proximidade da área central" (SOARES, 1965, p. 361). O que Soares chama de "valor potencial grande" pode ser o embriáo de uma teorização mais aprofundada do conceito de rent gap para a realidade do projeto Porto Maravilha.

\section{TEORIA DA GENTRIFICAÇÃO}

O primeiro uso do termo gentrificação aparece em um trabalho de Ruth Glass publicado em 1964, no qual a autora pesquisa o distrito londrino de Islington. Nesse momento, o fenômeno urbano da gentrificação ainda se apresentava de maneira bastante tímida. Poucos poderiam imaginar que, a partir dos anos 1970, ele assumiria uma dimensão central e emergiria como um novo modelo de urbanismo. No início deste século, a gentrificação adquiriu um caráter generalizado. Com efeito, uma realidade absolutamente local e identificada, em seu início, apenas nas grandes cidades de capitalismo avançado tornou-se mundial (SMITH, 2006, p. 61-62).

Como um modelo de desenvolvimento urbano a ser seguido, o fenômeno da gentrificação expandiu-se também para as principais cidades de países periféricos: Cidade do Cabo, Cidade do México, Xangai, Buenos Aires, São Paulo e Rio de Janeiro. Smith (2006, p. 62) destaca que os casos de gentrificação são os mais variados e diversificados, pois, ao mesmo tempo em que estão imersos em redes globais, possuem particularidades locais e articulaçóes econômicas em escalas nacionais.

Os sinais iniciais da gentrificação, como observa Smith (1979; 1996), surgiram ainda nos anos 1950 e ampliaram-se nas duas décadas seguintes. Já nos anos 1970, a gentrificação havia alcançado muitas das principais cidades estadunidenses, europeias e australianas. Assim que esse movimento urbano se difundiu, a pesquisa acadêmica passou a lhe oferecer especial atenção. Nos últimos 40 anos, as causas e os efeitos da gentrificação são objeto de muitas investigaçôes em todo o mundo e há uma série de divergências no interior desse debate.

$\mathrm{Na}$ tentativa de interpretar a gentrificação, Smith (1996) identificou duas matrizes teóricas explicativas para sua gênese, as quais são hegemônicas desde o final dos anos 1970: por um lado, estão aquelas que dão ênfase a elementos culturais; e, por outro, as que destacam as dimensóes econômicas.

Para o primeiro grupo, a gentrificação ocorre devido a uma mudança cultural nas populaçôes de classe média, que passam a valorizar o centro das cidades como local de moradia. Jovens profissionais liberais, trabalhadores do setor terciário, famílias de poucos filhos (ou sem filhos), ao adotarem um novo estilo de vida, abandonam o sonho de morar no subúrbio (uma tradicional aspiração da classe média norteamericana) pelo desejo de residir nas áreas centrais. A explicaçáo para esse fato, segundo alguns autores, está na mudança dos padrôes de consumo desses grupos sociais. Assim, nas cidades pós-industriais, é o consumo, e não a produção, que dita os novos usos do solo urbano. A gentrificação seria uma expressão urbana da pósmodernidade. Já os pesquisadores do segundo grupo salientam que o custo de novas construçôes habitacionais aumenta conforme se amplia a distância em relação ao 
centro da cidade. Acrescente-se também que esse maior distanciamento do centro implica custos maiores de deslocamento, tanto em transporte público quanto privado. Tendo isso em vista, a reabilitação de áreas centrais se apresenta como uma resposta economicamente mais viável que a contínua expansão rumo aos subúrbios.

Essas duas hipóteses explicativas não se excluem; ao contrário, salienta Smith, elas são frequentemente apresentadas como complementares, além de compartilharem uma perspectiva essencial: "a ênfase na preferência dos consumidores e nas restriçóes dentro das quais essas preferências são implementadas" (SMITH, 1996, p. 50, traduçáo nossa). $\mathrm{O}$ autor sublinha, ainda, que ambas as matrizes possuem uma raiz nas teorias econômicas neoclássicas e, por consequência, sugerem que tanto o movimento de suburbanização ${ }^{5}$ quanto o de gentrificação são resultados de mudanças nas escolhas pessoais. Nesse sentido, os novos moradores de áreas gentrificadas seriam exsuburbanos arrependidos ou desiludidos. Vale pontuar, que a gentrificação foi tratada nos EUA como um "movimento de retorno à cidade"; esse ponto, em particular, será importante para compreender o caso do Porto Maravilha.

Smith $(1979$; 1996) apresenta uma crítica às teorias que dáo primazia à preferência pessoal na explicação da gentrificação. Por meio de informaçôes empíricas, ele refuta a hipótese de que a gentrificação seria propalada por ex-suburbanos. Os casos analisados, como Society Hill (Filadélfia, EUA), Jordaan (Amsterdã, Holanda), Baltimore (EUA), Washington (EUA), apontam que, entre os novos moradores das áreas gentrificadas, a minoria vinha dos subúrbios.

Se a escolha cultural e as preferências dos consumidores desvendam a gentrificação, isso significa dizer que essas preferências mudam de maneira simultânea. Algo difícil de se provar, já que a gentrificação não é um fenômeno exclusivo norte-americano, dada a sua escala global. Esse fato pressupóe que famílias em várias cidades do mundo, de modo sincrônico, tomem a decisão de mudar-se para áreas centrais.

O autor propóe uma outra explicação para a gentrificação, na qual são considerados os papéis de diversos atores: construtores, incorporadores, promotores, instituiçôes estatais e financeiras. Ele também salienta que uma teorização ampla da gentrificação tem de dar conta tanto do papel dos produtores quanto dos consumidores. Nesse caso, Smith sinaliza que as necessidades de produção e de lucro são elementos muito mais decisivos que a preferência dos consumidores. Há uma relaçáo dialética entre produção e consumo; a produção assume o protagonismo nessa relação: "o chamado renascimento urbano tem sido estimulado mais por forças econômicas do que culturais. Na decisão de reabilitar uma estrutura do centro da cidade, uma preferência do consumidor tende a se destacar acima das demais - a preferência pelo lucro" (SMITH, 1979, p. 540, tradução nossa).

Ao considerar esses pontos, uma teoria da gentrificação deve responder às seguintes questóes: por que alguns bairros são rentáveis à "renovação urbana” e outros, não? Quais são as condiçôes da lucratividade? As teorias de inspiração neoclássicas - isto é, da primazia das preferências dos consumidores - não dão conta de respondêlas, pois tomam a disponibilidade de áreas para gentrificaçáo como algo dado, e isso é justamente o que precisa ser esclarecido (SMITH, 1979; 1996).

Smith, sob influência do pensamento marxista, encontra na teoria do valortrabalho o aporte teórico para sua interpretação da renda da terra. Desse modo, ele afirma que, numa sociedade capitalista, tanto a terra quanto as benfeitorias construídas sobre ela são mercadorias (SMITH, 1996, p. 55). Todavia, estas últimas
5 É importante ressaltar que o conceito de subúrbio é distinto nos EUA e no Rio de Janeiro. No primeiro caso, trata-se de bairros de classe média, no segundo, de bairros ocupados por camadas sociais mais pobres. 
náo são de qualquer tipo; na verdade, possuem características particulares que as distinguem das demais mercadorias. Smith explica três delas. Em primeiro lugar, a propriedade privada garante ao proprietário o monopólio do uso da terra, ainda que as regulamentaçóes estatais imponham algumas restriçóes ao uso do solo (zoneamento urbano, desapropriação por interesse público).

Em segundo, a terra e os investimentos feitos sobre ela estão fixados no espaço, já seus valores variam. Os investimentos sobre a terra estão sujeitos a todas as influências sobre seus valores, mas há uma diferença essencial em relação às demais mercadorias: por um lado, o valor das construçôes influencia a renda da terra que os proprietários podem demandar; por outro, como a terra e as construçóes são inseparáveis, quando mudam de dono, o preço das edificaçóes também reflete o nível da renda da terra. Enquanto um pedaço de terra não necessita de manutenção para manter seu potencial de uso, as construçóes precisam ser conservadas (SMITH, 1996, p. 55-56).

Finalmente, diferente da terra, as construçôes sobre ela não são permanentes, apesar de terem um período longo de vida útil, tanto em termos físicos quanto de valores. Por essa razão, instituiçóes financeiras possuem um papel relevante no mercado imobiliário. Os padrōes de depreciação de capital representam uma variável decisiva para determinar se o preço de venda de uma edificação reflete o nível da renda da terra e, mais do que isso, qual a proporção desse reflexo (SMITH, 1996, p. 56).

No final do século XIX, nos principais centros urbanos dos países industrializados, a variação do valor da terra apresentava o formato de cone: o vértice sobre o centro urbano, com um declínio gradativo em direçâo às periferias. Esse clássico modelo cônico foi proposto por Homer Hoyt, nos anos 1930, em suas pesquisas sobre Chicago. O próprio Hoyt identificou uma anomalia no comportamento do gráfico. Havia um "vale" entre o cume do cone e as áreas periféricas, para o qual ele não havia dedicado muita atenção.

Com o processo de deslocamento das camadas média e alta em direção aos subúrbios das cidades norte-americanas, o comportamento do valor da terra se transformou; por consequência, o "vale" se tornou mais profundo e amplo. É justamente nesse movimento de transformaçáo que residem as explicaçôes de Smith (1996, p. 57) para a formaçáo das inner-cities - áreas próximas ao centro, habitadas por populaçóes mais pobres. Houve, nesse momento, um deslocamento do capital em direção aos subúrbios, onde as taxas de lucratividades eram maiores. Assim, uma combinação de negligência e desinvestimento deliberado iniciou um longo período de deterioração e falta de novos investimentos de capital na inner-city.

De acordo com Smith (1979, p. 542; 1996, p. 58), uma teoria da gentrificação tem de explicar detalhadamente o processo histórico de desvalorização da inner-city e, de forma mais precisa, como tal desvalorização produz a possibilidade de reinvestimentos lucrativos. Para ele, o elo principal aqui é a relação entre "valor da terra"” e "valor da propriedade". Assim, para dar conta dessa tarefa, o autor propóe a separação dos dois termos em quatro categorias: (a) valor da edificaçáo; (b) preço de venda da edificação e terreno; (c) renda da terra capitalizada; e (d) renda da terra potencial.

A teoria neoclássica, ao enfatizar a preferência do consumidor, explica o preço como uma relação entre demanda e oferta. Por sua vez, ao seguir a tradição marxista da teoria do valor-trabalho, Smith distingue o valor da edificação do seu preço. Se o valor de uma mercadoria é medido pela quantidade de força de trabalho socialmente necessária para produzi-la, uma edificação qualquer também pode ter seu valor 
mensurado pela força de trabalho empregada na sua construção. É apenas no mercado imobiliário que o valor é convertido em preço. Há aí uma estreita relação entre valor e preço. Apesar de o segundo refletir o primeiro, ambos não podem ser mecanicamente equalizados, alerta o autor, pois é preciso considerar as interferências da oferta e da procura e das demais nuances do mercado. Uma particularidade que se apresenta no mercado imobiliário o torna um pouco mais complexo, a saber: as edificaçôes, periodicamente, retornam ao mercado através da revenda. Além disso, é necessário levar em conta a taxa de depreciaçáo devido ao uso cotidiano ao longo do tempo e a taxa de apreciaçáo a partir dos investimentos em manutenção, reformas e reparos, que, consequentemente, acrescentam mais valor à edificação (SMITH, 1996, p. 59).

Figura 4: Gráfico do valor da terra na cidade de Chicago (1933) e a formação do "vale"

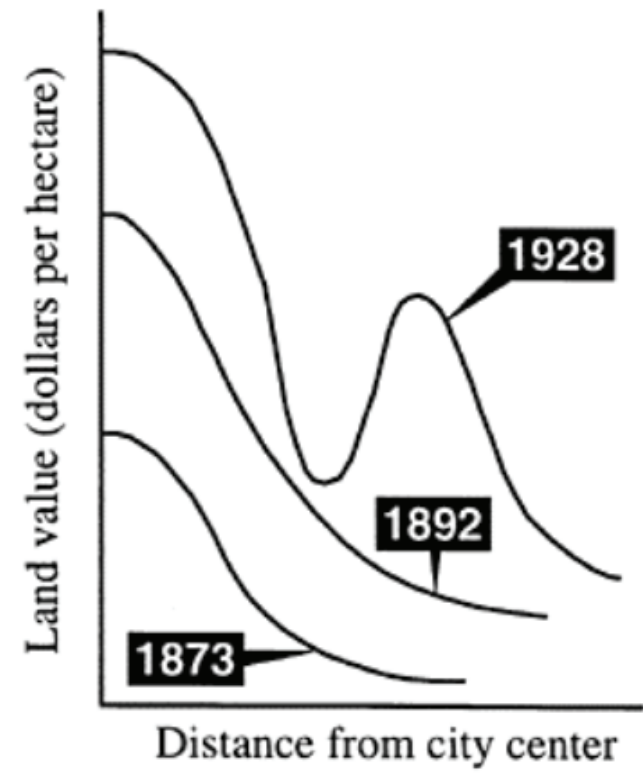

Fonte: Smith (1996, p. 58).

A categoria preço ainda exige mais algumas considerações. O preço de venda da edificação representa não somente o seu valor, mas também um componente adicional da renda, já que a terra é geralmente vendida com a sua estrutura. Portanto, aqui é preferível falar em renda da terra em vez de valor da terra, já que seu preço não reflete a quantidade de força de trabalho aplicado nela, como no caso do valor de uma mercadoria (SMITH, 1979, p. 542-543; 1996, p. 59).

A discussão a respeito da renda da terra possui uma longa tradição no campo da economia política, tendo recebido contribuiçôes teóricas de A. Smith, Malthus, Ricardo e Marx. Neil Smith também envereda por esse debate. Ele afirma que a renda da terra é uma reivindicação feita pelos proprietários pelo uso de sua terra e que representa uma reduçáo da mais-valia criada além do preço de custo dos produtores sobre o terreno. A renda da terra capitalizada se refere à real quantidade de renda da terra apropriada pelo proprietário, dado seu atual uso. No caso de aluguel imobiliário, as funçôes de produção e propriedade estáo combinadas, e a renda da terra se torna uma categoria ainda mais intangível, embora possua uma presença real. A renda da 
6 Nas poucas traduções dos textos de Smith, o termo rent gap é traduzido como "renda diferencial" ou "diferencial de renda". Neste texto, optou-se por manter a expressão em inglês para evitar qualquer confusão com o termo marxista differential rent. terra capitalizada do proprietário retorna principalmente na forma de aluguel pago pelo inquilino. No caso da ocupação do edifício pelo próprio proprietário, a renda da terra é capitalizada somente quando o imóvel é vendido e quando aparece como parte do preço de venda. Desse modo, conclui Smith, preço de venda = valor da edificação + renda da terra capitalizada (SMITH, 1979. p. 543; 1996, p. 59).

De acordo com seu atual uso da terra, um terreno ou um bairro, por exemplo, é capaz de capitalizar uma certa quantidade de renda da terra. Por razóes de localização, geralmente, uma área pode capitalizar maiores quantidades de renda da terra sob um uso diferente. A renda da terra potencial é a quantia que pode ser capitalizada sob o "maior e melhor uso" que se faz dela. Esse conceito é particularmente importante para explicar a gentrificação.

A partir das categorias citadas acima, o processo histórico que tornou alguns bairros predispostos à gentrificação pode ser delineado (SMITH, 1979. p. 543; 1996, p. 60). Smith demonstra que a deterioração física e a depreciação econômica da inner-city seguem uma lógica racional do mercado imobiliário, não se tratando de mudanças ao acaso. O declínio de um bairro é resultado de decisões de um conjunto de atores - privados e/ou governamentais. É possível deduzir a mesma ideia para o movimento oposto: a gentrificação também é resultado de decisóes econômicas de atores hegemônicos.

Feitas essas observaçóes, chega-se, pois, à teoria do rent gap ${ }^{6}$, que tem sido objeto de discussôes entre os pesquisadores dos fenômenos relacionados à gentrificação, desde que foi elaborada por Smith em 1979. Aqueles que fundamentam suas investigaçóes nas formulaçóes econômicas neoclássicas tendem a rejeitar tal teoria ou a impor-lhe tantas limitaçóes que ela se torna inaplicável. Alguns a admitem, mas destacam as suas limitaçóes; já outros a aceitam com entusiasmo.

O rent gap, nas palavras de Smith, é "a disparidade entre o nível de renda da terra potencial e a real renda da terra capitalizada sob o seu uso atual da terra" (SMITH, 1996, p. 65, tradução nossa). O rent gap é produzido principalmente pela desvalorização do capital (que diminui a proporção de renda da terra apta para ser capitalizada), bem como pela expansão e pelo contínuo desenvolvimento urbano (que, historicamente, têm aumentado o nível de renda da terra potencial na innercity). Dessa maneira, o "vale" identificado por Hoyt pode ser interpretado como uma ampliação do rent gap. A gentrificação está estreitamente relacionada ao rent gap, pois aquela só se realiza quando este é amplo o suficiente para que os investidores comprem imóveis e terrenos a preços reduzidos, paguem os custos e o lucro dos construtores para a requalificação urbana, cubram os juros sobre hipotecas e empréstimos de construção e, posteriormente, vendam o produto final por um preço capaz de lhes deixar uma satisfatória margem de lucro (SMITH, 1979, p. 545; 1996, p. 65).

Para Smith (1979, p. 546; 1996, p. 66), a gentrificação não é uma ocorrência ao acaso. Pelo contrário, é esperada. A desvalorização do capital em inner-cities do século XIX, paralelo ao crescimento urbano contínuo durante a primeira metade do século XX, produziu as condiçóes para que o reinvestimento rentável fosse possível. Se a teoria do rent gap está correta, a requalificação deve ocorrer onde o gap é maior e os retornos disponíveis são mais elevados, ou seja, em bairros próximos ao centro da cidade, particularmente.

O autor também destaca o papel do Estado nesse processo. Em suas pesquisas sobre os primeiros casos de gentrificação nos EUA, ele observa que o Estado se incumbiu 
de reunir as propriedades com preços de mercado, retornando-as aos investidores com preços subavaliados. O Estado suportou os custos nos últimos estágios da desvalorização do capital e, assim, garantiu aos investidores os mais elevados retornos financeiros, sem os quais a requalificação urbana da área não teria acontecido. Além disso, foi bem-sucedido economicamente, pois proporcionou as condiçóes gerais para a revitalização do mercado privado (SMITH, 1996, p. 67). Em Society Hill, na Filadélfia, onde dedicou boa parte de suas investigaçôes, Smith notou que o governo federal foi duplamente decisivo, isto é, atuou na construção de um arcabouço jurídico, que regulamentou as renovaçóes urbanas, e na desapropriação por interesse público (SMITH, 1996, p. 120-123). É necessário ter certo cuidado na compreensão do papel do Estado, isto porque a participação dele contempla uma grande diversidade de açôes nos episódios de gentrificação em todo o mundo, logo qualquer generalização soaria bastante vaga.

Destaque-se, ainda, que Smith afirma que a gentrificação é um produto estrutural do mercado imobiliário e de terras. O capital desloca-se para onde a taxa de retorno é mais elevada, e o movimento do capital aos subúrbios, ao longo da contínua desvalorização da inner-city, produz, eventualmente, o rent gap. Quando este é suficientemente amplo, o capital retorna aos bairros anteriormente deteriorados. Smith dá razão àqueles que defendem a gentrificação como um "movimento de retorno à cidade", conforme ressaltam as propagandas dos empreendedores do mercado imobiliário. Porém, ele faz referência a um retorno do capital, não das pessoas.

\section{AS CRÍTICAS AO RENT GAP}

Após sua publicação, a teoria do rent gap foi objeto de inúmeras discussóes, realizadas, fundamentalmente, por pesquisadores de países centrais. Muitas críticas foram apontadas, e o próprio Neil Smith reconheceu o mérito de algumas delas. Talvez o principal limite da teoria seja a sua difícil operacionalização - e é justamente esse ponto que será tratado mais adiante, a partir do caso particular do projeto Porto Maravilha. A presente seção busca assinalar algumas das críticas feitas à teoria do rent gap.

Alguns pesquisadores rejeitam a existência do rent gap. Fundamentado na experiência canadense de gentrificação, Ley (1986, p. 529, tradução nossa) defende que "a tese do rent gap não é confirmada pelos resultados". Ele não sustenta a relação entre a revitalizaçáo e o mercado imobiliário, pois seus dados demonstram que a gentrificação ocorreu em inner-cities com preços de imóveis mais elevados que a média metropolitana. Para Ley, a gentrificação é explicada pelas "amenidades urbanas", ou seja, a escolha por parte de alguns proprietários de um pacote de amenidades urbanas oferecidas pelo centro da cidade, não encontradas nos subúrbios, como o acesso a empregos. $\mathrm{O}$ autor sugere, inclusive, que essas escolhas estão associadas a movimentos de contracultura, a artistas de vanguarda, comunidades gays e ativistas de associaçôes políticas. Como conclusão, ele pontua que "há um revitalizante efeito recíproco e acumulativo da interação entre a oferta de empregos do centro da cidade e a qualidade de vida de áreas centrais" (LEY, 1986, p. 532, tradução nossa). Os argumentos desse pesquisador o colocam no já citado grupo dos que defendem a 
7 "A definição conceitual de Ley para o rent gap é severamente distorcida desde o início. Ele a redefine como uma característica da 'dinâmica do mercado imobiliário', sem referência direta ao mercado de terras, e ele a divorcia de um processo econômico mais amplo [...] em que o rent gap está incorporado e a partir do qual se desenvolve" (SMITH, 1987, p. 463, tradução nossa)

8 "A existência do rent gap é apenas uma explicação parcial" (SMITH, 1986, p. 25, tradução nossa). "soberania dos consumidores" como aspecto primordial para explicar a gentrificação. Em resposta a tal crítica, Smith (1987) afirma que Ley não compreendeu nem conseguiu operacionalizar o rent gap. ${ }^{7}$

Hamnett (1991), por sua vez, argumenta que as duas perspectivas teóricas (consumo x produção), apesar de focarem em diferentes aspectos, não são antagônicas, pelo contrário, são complementares. No entanto, Hamnett faz algumas críticas ao trabalho de Smith. Para ele, a relutância de Smith em aceitar o papel da nova classe (média), das características culturais e de consumo dela, assim como em enxergar qualquer papel significativo dos atores individuais limita o valor de sua abordagem para explicar a gentrificação. $\mathrm{Na}$ ótica de Hamnett, embora o rent gap seja necessário para que a gentrificação ocorra, ele não é suficiente.

Há ainda um outro autor que segue uma linha argumentativa semelhante à de Hamnett. Eric Clark (1988) propôs a realização de um teste empírico do rent gap, a partir da experiência de seis localidades em Malmö, Suécia. Após analisar os dados demográficos e do mercado imobiliário local, ele concluiu que "os seis casos revelavam um quadro bastante claro de rent gap", e que, além disso, "as evidências empíricas dos casos estudados apoiavam a visão destacada por Smith" (CLARK, 1988, p. 251-252, tradução nossa). Em outra passagem, Clark acrescenta que parece plausível sugerir que o rent gap se constitui como uma importante condiçâo para decisōes e açôes das formas de requalificação urbana. Ele deixa claro que a teoria do rent gap náo pode cumprir o duvidoso desejo de ser uma explicação completa para as várias formas de requalificação urbana, como o próprio Smith admitiu mais tarde ${ }^{8}$; apesar disso, dificilmente alguém pode ser contra ela (CLARK, 1988, p. 245).

\section{OS LIMITES E AS VIRTUDES DA TEORIA DO RENT GAP: O CASO DO PROJETO PORTO MARAVILHA}

A ideia aqui é verificar se o rent gap pode ser usado como uma ferramenta teórica que ajude a explicar o projeto Porto Maravilha. Entretanto, é necessário ter alguma cautela nessa tarefa, em funçấo das observações expostas a seguir. A primeira delas diz respeito ao fato de que o rent gap foi formulado a partir de experiências em países centrais, especialmente nos Estados Unidos e na Europa, o que implica algumas adaptaçóes para trazê-lo para o Rio de Janeiro, metrópole de um país inserido perifericamente na economia-mundo. Mais do que isso, a própria formação da urbe carioca a torna bem diferente das cidades norte-americanas e europeias.

Existem, contudo, argumentos que fazem crer que o rent gap contribui para compreender a "revitalização" da zona portuária do Rio. O modo de produção capitalista produz o espaço urbano de maneira diferente em cada parte. Mesmo os espaços urbanos produzidos dentro de um mesmo país podem se revelar bastante distintos. A despeito das idiossincrasias de cada espaço urbano, as lógicas de produção espacial que operam sob o domínio do capital possuem um sem-número de características comuns, como mostrou Henri Lefebvre em diversas publicaçôes, e essa é a lógica do mercado. Do contrário, como sustentar que grandes cidades de diferentes continentes experimentaram, simultaneamente, um processo de degradação de bairros próximos ao 
centro e, posteriormente, a gentrificação - o outro lado da mesma moeda? É possível explicar isso somente se se aceita que há algum somatório de elementos capaz de orientar a produção do espaço. Ou, então, deve-se aceitar que tudo é uma coincidência sincrônica.

A segunda precaução está ligada ao fato de que os processos relacionados à gentrificação desenvolveram-se nas cidades dos países centrais a partir da segunda metade do século XX. Já o caso carioca do Porto Maravilha - semelhante ao de outras cidades latino-americanas - manifestou-se com algumas décadas de atraso. Isso implica que, em consonância com a dinâmica do mercado global, a atuação de alguns atores apresente mudanças. Assim, a lógica de atuaçáo do grande capital internacional na produção do espaço urbano, ainda que apresente elementos centrais comuns, expressa algumas variaçôes em função da conjuntura. Por exemplo, a célebre marca norte-americana de arranha-céus, as Trump Towers, já manifestou o interesse de investir no Porto Maravilha (cinco torres comerciais de 38 andares) ${ }^{9}$. Pode-se supor que esse movimento tenha sido influenciado pela recente crise imobiliária nos EUA. Nesse sentido, os investidores do ramo imobiliário estariam ávidos por deslocar o seu capital para mercados emergentes - onde esperam conseguir taxas maiores de lucratividade.

$\mathrm{O}$ terceiro cuidado refere-se à dificuldade de aplicar o rent gap em um caso concreto - dificuldade decorrente dos obstáculos para medir a renda da terra potencial e a renda da terra capitalizada, já que, em sua formulação, Smith explica que o rent gap é a diferença entre a renda da terra potencial (no seu maior e melhor uso) e a real renda da terra capitalizada, sob seu uso atual da terra. O próprio Neil Smith admite a complexidade da operacionalização ${ }^{10}$.

Ele sugere que o "preço de venda = valor da edificação + renda da terra capitalizada". O valor da edificação - isto é, o tempo de força de trabalho socialmente necessário para construí-la - não pode ser medido facilmente. Porém, esse valor, em uma mesma conjuntura econômica, não deve variar significativamente entre distintos bairros. Supóe-se que o valor para construir uma edificação idêntica não apresente grandes variaçôes, independentemente do bairro. Apenas quando o valor se transforma em preço (com as interferências do mercado, localização, oferta e demanda, amenidades etc.), ocorre uma diferença. Assim, é possível considerar o valor da edificação como uma constante. Por opção metodológica, a partir da equação acima, o preço de venda deve ser uma aproximação da renda da terra capitalizada. Nesse caso, interessa a oscilaçáo de preços entre os bairros ao longo de um determinado recorte temporal.

De antemáo, pode-se afirmar que apenas os preços das edificações náo são suficientes para dar conta da tarefa. Para melhor perceber a gentrificação, Smith salienta a necessidade de combinar alguns indicadores:

Por definição, indicadores são sempre aproximações ao significado do conceito, mas no caso da gentrificação é possível conseguir aproximaçóes mais precisas. Para capturar mudanças no mercado imobiliário, algumas medidas, como preço dos imóveis e/ou níveis de aluguel, são também importantes. A combinação de indicadores de renda e aluguéis é muito mais satisfatória (SMITH, 1987, p. 463, tradução nossa).

Em função do caráter inicial do projeto Porto Maravilha, ainda não se dispõe de dados sobre a transição do perfil demográfico da zona portuária. Neste artigo são usados somente os dados do mercado imobiliário. Para tanto, optou-se por utilizar os
9 Disponível em: <http:// www.trumptowersio. com/>. Acesso em: 10 de abr. 2015.

10 "É um conceito difícil de operacionalizar" (SMITH, 1996, p. 69, tradução nossa). 
11 Disponível em: <www. zap.com.br/imoveis/fipezap/>. Acesso em: 25 maio. 2014.

12 O bairro Saúde ficou de fora da análise, pois, durante a pesquisa, não possuía amostras suficientes de anúncio de venda de imóveis.

130 ponto zero está localizado no cruzamento entre as avenidas Rio Branco e Presidente Vargas. preços médios na venda de apartamentos, medidos pela FipeZap ${ }^{11}$. Seguem algumas observaçôes sobre os dados do Gráfico 1.

A Fundação Instituto de Pesquisa Econômica (Fipe), em parceria com um jornal de grande circulação, passou a monitorar o mercado imobiliário há alguns anos. Os dados da Tabela 1 e do Gráfico 1 são referentes ao preço médio de venda de apartamentos (independente do número de dormitórios), por metro quadrado, praticado pelo mercado em cada bairro selecionado e divulgado nos classificados dos principais diários cariocas. Sabe-se que o preço anunciado não é, necessariamente, o preço de venda, contudo, é próximo o suficiente para que justifique a comparação entre os bairros selecionados. Trata-se do único índice que permite fazer comparaçóes entre períodos desde 2008.

Foram selecionados os bairros da zona portuária ${ }^{12}$, o centro e alguns bairros imediatos das Zonas Sul e Norte (Figura 5). Para mensurar a relaçáa entre o preço dos imóveis e a distância entre os bairros, foi definido um ponto de referência no centro (ponto zero) ${ }^{13}$, assim como em cada um dos bairros selecionados. Nos períodos escolhidos (julho/2009, janeiro/2012 e abril/2014), analisou-se a variação dos dados em três momentos: antes do lançamento do projeto Porto Maravilha e em dois intervalos posteriores, com períodos aproximados de 30 meses entre eles, de modo a notar o comportamento do mercado.

O resultado pode ser visto no Gráfico 1. O objetivo aqui é perceber o rent gap na zona portuária. Portanto, escolheu-se como referência espacial o centro da cidade e dois vetores: um em direção à Zona Sul, onde se localizavam os tradicionais bairros das camadas mais elevadas, e outro em direção aos bairros imediatos da Zona Norte, ocupados por populaçôes de camadas médias e baixas.

A análise do gráfico parece ratificar as teorias de Smith sobre gentrificação e rent gap. Nos dados referentes a julho de 2009, antes do lançamento do projeto Porto Maravilha, observa-se um pequeno "vale" formado na zona portuária (Santo Cristo e Gamboa). Enquanto nesses bairros os preços se situam próximos a $R \$ 1.500 / \mathrm{m}^{2}$, nos bairros mais imediatos, os preços ultrapassam os $\mathrm{R} \$ 4 \mathrm{mil} / \mathrm{m}^{2}$ (Catete) ou $\mathrm{R} \$$ $3 \mathrm{mil} / \mathrm{m}^{2}$ (Glória). E elevam-se ainda mais em direção à Zona Sul. No vetor norte, os preços alcançam por volta de $\mathrm{R} \$ 2.300 / \mathrm{m}^{2}$ (Tijuca, Maracanã e São Cristóvão). Considerando apenas esses resultados, o "vale" que se forma no gráfico é ainda pouco acentuado.

O "vale" aprofunda-se e alarga-se trinta meses depois. Em janeiro de 2012, os bairros portuários atingem preços próximos a $\mathrm{R} \$ 3.100 / \mathrm{m}^{2}$. No vetor sul, Glória e Catete alcançam $\mathrm{R} \$ 7.700 / \mathrm{m}^{2}$ e $8.500 / \mathrm{m}^{2}$, respectivamente. Em direçáo aos bairros litorâneos, os preços ultrapassam os $\mathrm{R} \$ 10 \mathrm{mil} / \mathrm{m}^{2}$. Por sua vez, em direção à Zona Norte, a Tijuca e arredores alcançam preços por volta de $\mathrm{R} \$ 5 \mathrm{mil} / \mathrm{m}^{2}$. Segundo a ótica de Smith, pode-se interpretar esse aprofundamento e alargamento do "vale" como uma ampliação do rent gap. Desse modo, os bairros portuários converteram-se em espaços preferenciais para o investimento imobiliário, já que têm um maior potencial de crescimento e, consequentemente, uma maior taxa de lucratividade. Boa parte do aprofundamento tal gap está relacionada ao lançamento do projeto Porto Maravilha e ao anúncio das obras viárias na localidade. 
Tabela 1: Preços correntes de venda, por metro quadrado, de imóveis em bairros selecionados, em três períodos diferentes

\begin{tabular}{|c|c|c|c|c|}
\hline Bairro & $\begin{array}{c}\text { Distância em relaçáo } \\
\text { ao centro }(\mathbf{m})\end{array}$ & $\begin{array}{c}\mathrm{ABR} / 14 \\
\mathrm{R} \$\end{array}$ & $\begin{array}{c}\text { JAN/12 } \\
\text { R\$ }\end{array}$ & $\begin{array}{c}\text { JUL/09 } \\
\text { R\$ }\end{array}$ \\
\hline Eng. Novo & -12.956 & $3.971,00$ & $2.734,00$ & $1.322,00$ \\
\hline Grajaú & -11.204 & $5.920,00$ & $4.228,00$ & $1.887,00$ \\
\hline Andaraí & -9812 & $6.051,00$ & $4.355,00$ & $2.093,00$ \\
\hline Tijuca & -7779 & $7.335,00$ & $5.214,00$ & $2.339,00$ \\
\hline Maracanã & -6322 & $6.917,00$ & $5.027,00$ & $2.217,00$ \\
\hline S. Cristóvão & -4503 & $6.150,00$ & $4.095,00$ & $2.397,00$ \\
\hline Sto. Cristo & -2576 & $4.727,00$ & $3.088,00$ & $1.667,00$ \\
\hline Gamboa & -2064 & $6.757,00$ & $3.296,00$ & $1.457,00$ \\
\hline Centro & 0 & $8.280,00$ & $6.058,00$ & $3.036,00$ \\
\hline Glória & 2.207 & $9.965,00$ & $7.776,00$ & $3.025,00$ \\
\hline Catete & 2.794 & $10.890,00$ & $8.494,00$ & $4.310,00$ \\
\hline Laranjeiras & 3.502 & $10.665,00$ & $8.400,00$ & $4.024,00$ \\
\hline Flamengo & 4.003 & $11.050,00$ & $8.752,00$ & $4.311,00$ \\
\hline Botafogo & 5.463 & $11.858,00$ & $9.038,00$ & $4.461,00$ \\
\hline Copacabana & 7.688 & $11.466,00$ & $9.534,00$ & $4.508,00$ \\
\hline Ipanema & 10.412 & $13.153,00$ & $12.063,00$ & $7.534,00$ \\
\hline Leblon & 12.205 & $12.749,00$ & $12.779,00$ & $8.155,00$ \\
\hline S. Conrado & 15.497 & $11.685,00$ & $9.629,00$ & $4.815,00$ \\
\hline
\end{tabular}

Fonte: FipeZap (Disponível em: <http://www.zap.com.br/imoveis/fipe-zap-b/>. Acesso em: 5 mai. 2014).

Gráfico 1: Preços correntes de venda de imóveis no município do Rio de Janeiro (bairros selecionados)

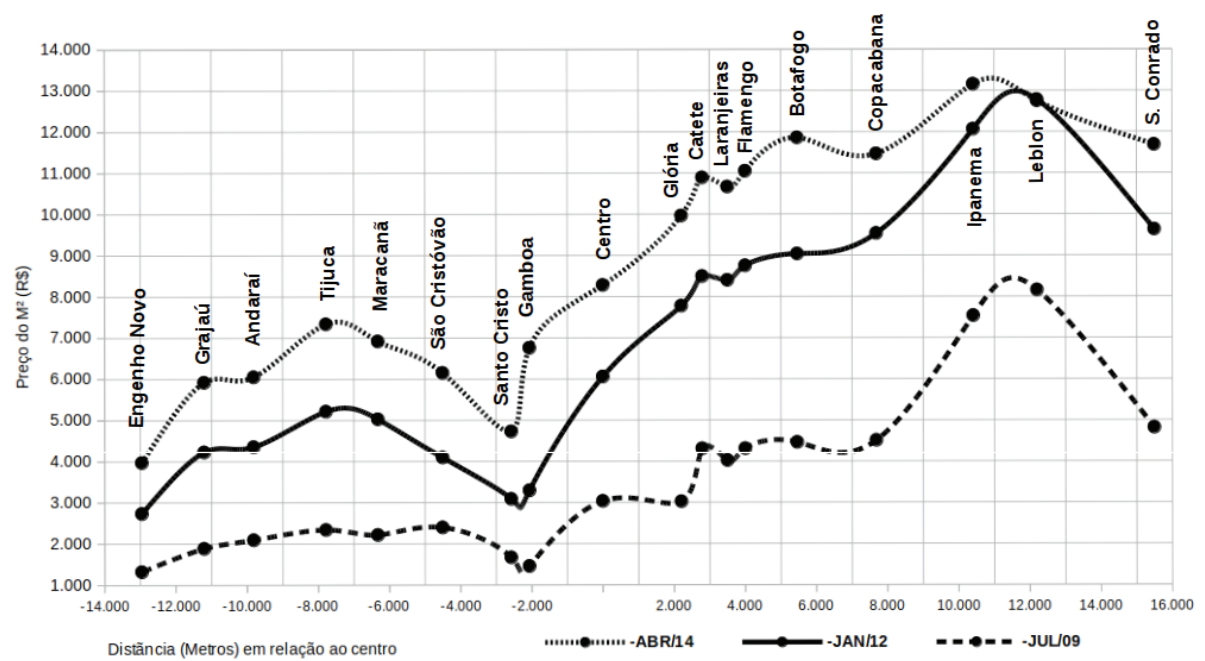

Fonte: FipeZap (Disponível em: <http://www.zap.com.br/imoveis/fipe-zap-b/>. Acesso em: 5 mai. 2014). 
Dados mais recentes (abril de 2014) demonstram que os preços médios dos imóveis nos bairros portuários e no entorno continuam a elevar-se. Entretanto, percebe-se que o "vale" tem se tornado menos profundo. Esses últimos dados são posteriores ao início da execução das obras no Porto Maravilha. O mercado imobiliário local se aqueceu e assistiu à elevação dos preços. A partir daí, é razoável concluir que o "potencial” da renda da terra está sendo "consumido". Se essa tendência prosseguir, o "vale" deve reduzir-se até o instante em que não for mais do interesse do mercado imobiliário investir da mesma maneira, já que a taxa de lucratividade também tende a diminuir.

Figura 5: Bairros selecionados do Rio de Janeiro

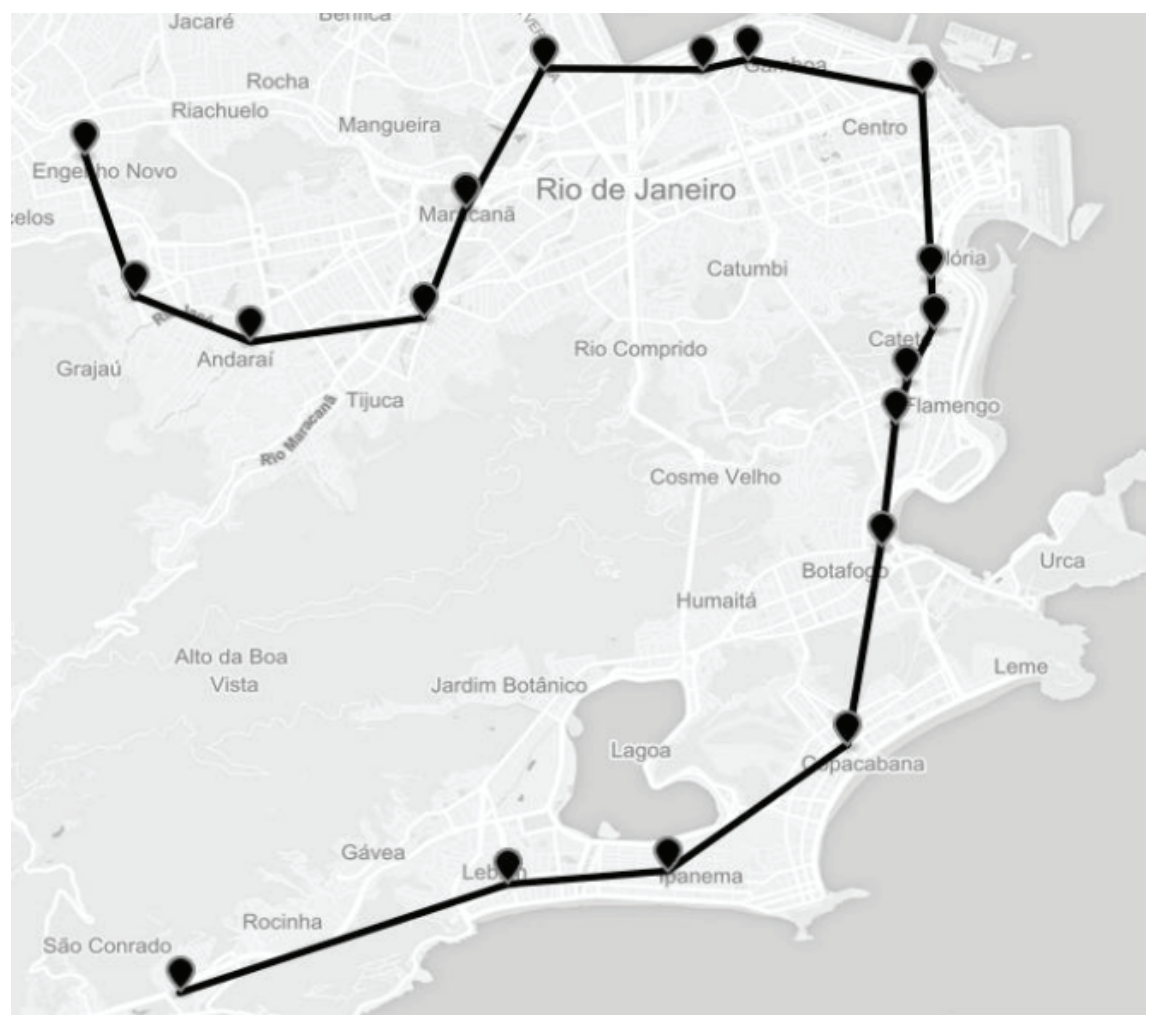

Fonte: Elaborado pelo autor a partir da ferramenta MapBox.

Percentualmente, o bairro Gamboa foi, entre os selecionados, aquele que mais se valorizou entre julho de 2009 e abril de 2014 - aproximadamente $364 \%$. O restante dos bairros apresentou os seguintes índices: Glória (229\%), Tijuca (213\%), Santo Cristo (184\%), São Cristóvão (156\%), Centro (172\%), Botafogo (165\%), Ipanema (74\%) e Leblon (56\%). 


\section{CONSIDERAÇÕES FINAIS}

É possível apresentar alguns apontamentos preliminares a partir das discussóes realizadas até aqui.

Parte-se da ideia de que as formulaçóes teóricas sobre a gentrificação e o rent gap de Smith são úteis para entender o episódio carioca, apesar de não darem conta de todo o processo, conforme a crítica de alguns pesquisadores já citados.

A zona portuária do Rio de Janeiro atravessou um período de deterioração física e econômica a partir da década de 1950. Esse processo é comumente chamado de filtering $^{I 4}$ pela literatura acadêmica anglófona de inspiração neoclássica. Tal conceito foi desenvolvido por Brian Berry, que o explica da seguinte forma: quando novas edificações são construídas, elas são ocupadas, em geral, por famílias de renda mais elevada. As edificaçôes anteriores deixadas por essas famílias são "filtradas" para famílias de renda inferior. Em cadeia, cada família ocupa uma residência melhor, deixada por uma família de renda superior, e, por conseguinte, libera uma residência para uma família de renda inferior. O limite do processo ocorre quando os piores imóveis saem do mercado por abandono ou demolição (BERRY, 1980, p. 16). Portanto, o filtering seria a explicação para a deterioração física e o esvaziamento econômico sofridos por alguns bairros próximos aos centros das cidades.

O modelo de filtering não contribui para o exemplo do Rio de Janeiro, pois a deterioraçáo dos bairros portuários ocorreu mais em funçáo da transferência de indústrias para pontos mais distantes do centro e do declínio das atividades portuárias do que pelo deslocamento de famílias de renda mais elevada para bairros mais valorizados. A proposição de Smith (1996, p. 60) de que "nós podemos pensar n[a] explicação [do rent gap] como uma correção, pelo lado da produçáo, do tradicional conceito de 'filtering" tampouco ajuda, porque aparenta ser mais adequada à realidade do sistema urbano estadunidense. Todavia, é válida a seguinte observação. A deterioração econômica de determinadas áreas da cidade náo deve ser entendida como inevitável, uma vez que são os agentes das forças de mercado que a produzem. Os mecanismos que perpassam o filtering são a depreciação e a desvalorização do capital investido em inner-cities, portanto, decisóes de mercado. Tal desvalorização produz as condiçôes econômicas objetivas que fazem da valorização do capital (gentrificação) uma resposta racional do mercado, o que é chamado por Smith de rent gap.

Eis uma importante contribuição de Smith para entender o Porto Maravilha. Tanto o já citado processo de deterioraçáo física e de esvaziamento econômico da zona portuária durante a segunda metade do século XX, quanto o recente movimento para gentrificá-la são resultados das escolhas e da correlação de forças dos agentes de mercado - órgãos governamentais, proprietários de terra e de imóveis ou instituiçôes financeiras. O próprio processo de deterioração de um bairro não é visto necessariamente de maneira negativa pelo mercado imobiliário, pois se apresenta como uma grande oportunidade de negócio. A gentrificação ocorre justamente quando o rent gap é amplo o suficiente.

O trabalho de Smith ajuda a perceber que a gentrificaçáo deixou de ser uma "anomalia local" para se tornar uma estratégia urbana global generalizada (SMITH, 2006). Essa é uma das polêmicas dele com Clark (2005), que questiona se a generalização é realmente uma novidade, dado que, de alguma maneira, o alcance global do fenômeno não seria recente.

\begin{abstract}
140 filtering, ou filtering down, como já foi chamado no passado, é o oposto da gentrificação. Ocorre quando as famílias que se mudam para determinado bairro são de nível socioeconômico mais baixo que o daquelas que se movem para fora. Entendido como um processo de mudança espacial, social e urbana, ele é associado à Escola de Chicago, particularmente ao modelo de zonas concêntricas de E. Burgess e, mais ainda, ao modelo setorial de uso da terra de H. Hoyt (CLARK, 2010).
\end{abstract}


A generalização da gentrificação, argumenta Smith (2006, p. 75-78), possui algumas características centrais interligadas, como o novo papel do Estado, o protagonismo dos governos locais e a parceria com o capital privado - características que se destacam como elementos comuns em diversas experiências internacionais. $\mathrm{O}$ caso carioca é um bom exemplo, já que o projeto tem sido conduzido por um consórcio do qual participa a prefeitura municipal e algumas empresas privadas. Vê-se a presença do capital financeiro e do novo papel desempenhado pela globalizaçáo do capital. Nesse ponto, a intenção de construção das Trump Towers no Rio é emblemática. Há diversas empresas internacionais envolvidas no projeto, conforme mostra a página eletrônica do empreendimento. A resistência contra a gentrificação também tem sido observada em escala global - Berlim, Nova Iorque, Vancouver, São Francisco, Paris são alguns dos casos citados por Smith. No Rio de Janeiro, o Fórum Comunitário do Porto produziu um relatório, publicado em maio de 2011, que destaca as violaçóes de direitos e as reivindicaçóes dos moradores.

Cabe destacar, ainda, alguns aspectos do caráter classista da gentrificação. Trata-se de uma produção de paisagens urbanas que precisam ser consumidas pelos novos moradores de renda mais elevada. A lógica do mercado, e não mais a dos financiamentos de serviços sociais, é que serve de orientação para as políticas urbanas (SMITH, 2006, p. 80).

O debate sobre o rent gap foi levado adiante por muitos pesquisadores de países centrais, porém foi deixado de lado nas reflexôes sobre as experiências de renovaçóes urbanas no Brasil. A despeito de serem indissociáveis na ótica de Smith, o termo gentrificação obteve expressivo alcance nos estudos urbanos brasileiros; afirmação semelhante náo pode ser feita para o caso do rent gap.

Antes de finalizar, reconhece-se que, a partir deste artigo, vários pontos devem ser aprofundados. Por exemplo, é necessário levantar mais dados sobre o mercado imobiliário, verificar a transiçáo do perfil dos moradores dos bairros portuários e pôr tais informaçóes em escrutínio. Igualmente, outros indicadores precisam ser incorporados à análise, assim como outras experiências de aplicação empírica do rent gap. A zona portuária encontra-se em pleno curso de transformação, e esse fato impóe algumas limitaçóes metodológicas.

Por essas razōes, é oportuno sugerir alguns elementos para uma possível agenda de pesquisa. O monitoramento do mercado imobiliário local trará informaçóes sobre uma eventual mudança do perfil demográfico dos bairros portuários. Por pressão de movimentos populares de luta por moradia, encontra-se em discussão nos órgãos municipais o Plano de Habitação de Interesse Social do Porto. Acompanhar o plano e a sua execução é uma tarefa relevante na verificação de algum efeito considerável nesse espaço urbano. Observar a participação do Estado nos casos de gentrificação e realizar um estudo comparativo com experiências internacionais podem ser açôes úteis para compreender a diversidade das atuaçóes governamentais. Enquanto em alguns casos os governos são sutis, no episódio carioca, eles desempenham açóes decisivas. 


\section{REFERÊNCIAS}

BERRY, B. Inner-city futures: an American dilemma revisited. Transactions of the Institute of British Geographers, n. 5, p. 1-28, 1980.

CLARK, E. The rent gap and transformation of the built environment: case studies in Malmö 1860-1985. Geografiska Annaler, v. 70, n. 2, p. 241-254, 1988.

. On gaps in gentrifiction theory. Housing Studies, v. 7, n. 1, p. 16-26, 1992.

The rent gap re-examined. Urban Studies, v. 32, n. 4, p. 1489-1503, 1995.

The order and simplicity of gentrification: a political challenge. In: ATKINSON,

R. \& BRIDGE, G. (Ed.). Gentrification in a global context: the new urban colonialism.

New York: Routledge, 2005. p. 261-269.

. Filtering. Encyclopedia of Geography, 2010. Disponível em <http://www.sage-ereference.com/geography/Article_n429.html>. Acesso em: 5 maio de 2015.

FREITAS FILHO, A.P. A indústria do Rio de Janeiro no início da década de 1960 e o pensamento dos industriais cariocas sobre a fusão (1960-75). In: ENCONTRO REGIONAL DE HISTÓRIA, 11., 2004, Rio de Janeiro. Anais do XI Encontro Regional de História. Rio de Janeiro: ANPUH-RJ, v.1, 2004. Disponível em: <http://www.rj.anpuh.org/ resources/rj/Anais/2004/Simposios\%20Tematicos/Almir\%20Pita\%20Freitas\%20 Filho.doc>. Acesso em: 7 dez. 2015.

GEIGER, P. Ensaio para a estrutura urbana do Rio de Janeiro. Revista Brasileira de Geografia, v. 22, n. 1, p. 3-46, jan./mar. 1960.

GLASS, R. London: aspects of changes. London: Centre for Urban Studies and MacGibbon and Kee, 1964.

HAMNETT, C. The blind men and the elephant: the explanation of gentrification. Transactions of the Institute of British Geographers, v. 16, n. 2, p. 173-189, 1991.

LAMARÃO, S. T. N. Dos trapiches ao porto: um estudo sobre a área portuária do Rio de Janeiro. 2. ed. Rio de Janeiro: Secretaria Municipal de Cultura, 2006.

LEY, D. Alternative explanations for inner-city gentrification: a canadian assessment. Annals of Association of American Geographers, v. 76, n. 4, p. 521-535, 1986.

OSORIO, M.; VERSIANI, M. H. O papel das instituiçôes na trajetória econômico-social do Estado do Rio de Janeiro. Cadernos do Desenvolvimento Fluminense, Rio de Janeiro, n. 2, p. 188-210, jul. 2013.

SMITH, N. Toward a theory of gentrification: a back too a city movement by capital, not people. Journal of the American Planning Association, v. 45, n. 4, p. 538-548, 1979.

. Gentrification and rent gap. Annals of Association of American Geographers, v. 77, n. 3, p. 462-465, 1987.

New urban frontier: gentrification and the revanchist city. London: Routledge, 1996.

. A gentrificação generalizada: de uma anomalia local à "regeneração" urbana como estratégia urbana global. In: BIDOU-ZACHARIASEN (Ed.). De volta à cidade: dos processos de gentrificação às políticas de "revitalização" dos centros urbanos. Sáo Paulo: Annablume, 2006. p. 59-87.

. Gentrificação, a fronteira e a reestruturação do espaço urbano. GeoUSP, São Paulo, n. 21, p. 15-31, 2007.

SOARES, M. T. S. Fisionomia e estrutura do Rio de Janeiro. Revista Brasileira de Geografia, Rio de Janeiro, n. 3, p. 329-387, jul./set. 1965. 
A B S T R A C T : The Operação Urbana Consorciada (OUC) Porto Maravilha refers to a set of urban interpositions on roads, real state and financial apport in the port area of Rio de Janeiro. The interpositions are performed by a consortium involving the municipal government and transnational contractors. The urban operation in question stands out from others because this is the largest brazilian public-private partnership. The aim of this paper is to perform an analysis of the OUC Porto Maravilh a from the theoretical rent gap formulation proposed by Neil Smith with the consequent discussion about the concept of gentrification. The purpose is to make sure that it can help to understand the urban interventions in Rio. In addition, it intends to examine the limits and virtues of the the rent gap. There are several issues to consider: Is it possible to "import" a theory formulated to cities of core countries and apply it in Rio experience? If so, what are the distinctions and precautions that should be outlined?

K E Y W O R D S : Porto Maravilha; gentrification; rent gap; urban entrepreneurship. 